\title{
HUBUNGAN POLA ASUH ORANG TUA OTORITER TERHADAP PERILAKU AGRESIF PADA REMAJA DI DESA PLALANGAN
}

\author{
Puput Chusnul Chotimah \\ Fakultas Usuhulludin, Adab, dan Dakwah IAIN Ponorogo \\ puputchusnul@gmail.com
}

\begin{abstract}
This study aims to determine the level of authoritarian parenting and adolescent aggressive behavior and to determine the relationship between authoritarian parenting and adolescent aggressive behavior in Plalangan Village. Authoritarian parenting patterns can affect behavior towards teenagers, teenagers become more depressed, parents pay less attention to teenagers but demand to be what they want, even parents compare with other teenagers so that teenagers become depressed, and parents are less supportive in the stimulus. adolescent development. The sample used is 80 respondents. Sampling technique with questionnaires and analysis used using test instruments, statistical tests, and hypothesis testing. The results of the study indicate that the level of authoritarian parenting is 80 respondents (65\%) of moderate level of authoritarian parenting. Then the aggressive behavior of teenagers as many as 80 respondents (61.3\%) teenagers experienced moderate level of aggressive behavior. Based on the hypothesis test, there is a significant relationship between authoritarian parenting and adolescent aggressive behavior at a significant level of $1 \% r$ count $=0.802>r$ table 0.219 then the alternative hypothesis is accepted.
\end{abstract}

Keywords: parenting, aggressive behavior, adolescents.

\begin{abstract}
Abstrak
Penelitian ini bertujuan untuk mengetahui tingkat pola asuh orang tua otoriter dan perilaku agresif remaja serta untuk mengetahui hubungan antara pola asuh orang tua otoriter dan perilaku agresif remaja di Desa Plalangan. Pola asuh otoriter orang tua dapat mempengaruhi perilaku terhadap remaja, remaja menjadi lebih tertekan, orang tua kurang memperhatikan remaja tetapi menuntut untuk menjadi yang dia inginkan, bahkan orang tua membandingkan dengan remaja-remaja lain sehingga remaja menjadi tertekan, serta orang tua kurang mendukung dalam stimulus perkembangannya remaja. Sampel yang
\end{abstract}


digunakan 80 responden. Teknik pengambilan sampel dengan kuesioner dan analisis yang digunakan mengunakan uji instrument, uji statistik, dan uji hipotesis. Hasil penelitian meninjukkan bahwa tingkat pola asuh orang tua otoriter sebanyak 80 responden $(65 \%)$ orang tua pola asuh otoriter tingkat sedang. Kemudian perilaku remaja agresif sebanyak 80 responden $(61,3 \%)$ remaja mengalami perilaku agresif tingkat sedang. Berdasarkan uji hipotesis terdapat hubungan yang signifikan antara pola asuh orang tua otoriter dengan perilaku agresif remaja pada taraf signifikan $1 \% \mathrm{r}$ hitung = 0,802> $\mathrm{r}$ tabel 0,219 maka hipotesis alternatif diterima.

\section{Kata kunci: pola asuh, perilaku agresif, remaja.}

\section{PENDAHULUAN}

Berdasarkan tata bahasanya, pola asuh terdiri dari kata pola dan asuh. Menurut kamus umum bahasa Indonesia, "kata pola berarti model, sistem, cara kerja, bentuk (struktur yang tetap), sedangkan kata asuh mengandung arti menjaga, merawat, mendidik, membantu anak agar dapat berdiri sendiri unutuk mengapai susuatu". "Pola asuh diartikan cara membimbing atau bimbingan yaitu bantuan pertolongan yang diberikan individu dalam menghindari atau mengatasi kesulitan dalam hidupnya agar supaya individu atau seorang individu itu dapat mencapai kesejahteraan hidupnya,2.

Pola asuh otoriter yaitu pola asuh dimana anak harus mengikuti pendapat dan keinginan orang tua, kekuasaan dipilih orang tua, anak tidak diperkenankan memberikan pendapat kepada orang tua. Orang tua cenderung kaku, suka bersikap dan melaksanakan kehendak, selalu mengatur tanpa memperhatikan kemauan dan perasaan anak. Sehingga dengan itu dapat disimpulkan bahwa anak dengan terpaksa mengikuti kehendak orang tua yaitu sekolah rendah meskipun anak itu mampu sekolah tinggi dan dapat mengejar cita-citanya, namun cita-cita tersebut kandas. ${ }^{3}$

Agresif adalah tingkah laku kekerasan secara fisik ataupun secara verbal terhadap individu lain atau terhadap objek. Agresif secara fisik meliputi kekerasan yang dilakukan secara fisik, seperti memukul, menampar, menendang dan lain sebagainya. Selain itu

\footnotetext{
${ }^{1}$ Tim Penyusun Kamus Pusat Bahasa, Kamus Bahasa Indonesia, (Jakarta: Balai Pustaka, 2002), 885.

${ }^{2}$ Bimo Walgito, Bimbingan dan Penyuluhan di Sekolah, (Yogyakarta: Fakultas Psikologi UGM, 1989), 5.

${ }^{3}$ Sitti Nurhalimah dkk, Media Sosial Dan Masyarakat Pesisir : Refleksi Pemikiran Mahasiswa Bidikmisi (Deepublish, 2019).157
} 
agresif secara verbal adalah penggunaan kata-kata kasar seperti bego dan tolol. Selain bentuk agresif tersebut, ada factor yang mempengaruhinya dalam perbuatan agresif diantaranya factor belajar, factor imitasi, dan faktor penguatan. ${ }^{4}$

Remaja sebagai masa peralihan dari masa anak ke masa dewasa, meliputi semua perkembangan yang dialami sebagai persiapan memasuki masa dewasa. Perkembangan yang jelas pada masa remaja ini adalah perkembangan psikoseksualitas dan emosionalitas. Batas usia yang digunakan adalah 12 tahun sampai 22 tahun. WHO mendefinisikan remaja ke dalam tiga kriteria yaitu biologik, psikologik, dan sosial ekonomi. Secara lengkap remaja didefinisikan sebagai suatu masa: individu berkembang dari saat pertama kali ia menunjukkan tanda-tanda seksual sekundernya sampai saat ia mencapai kematangan seksual, individu mengalami perkembangan psikologik dan pola identifikasi dari kanak-kanak menjadi dewasa, dan terjadi peralihan dari ketergantungan sosial-ekonomi yang penuh kepada keadaan yang relatif lebih mandiri. WHO menetapkan batas usia 10-20 tahun sebagai batasan usia remaja. ${ }^{5}$

\section{METODE PENELITIAN}

Penelitian ini termasuk dalam penelitian kuatitatif, dengan jenis korelasional. Variable bebasnya yaitu pola asuh otoriter dan variable terikatnya perilaku agresif remaja. subjek dalam penelitian ini adalah remaja plalangan yang berusia 12-18 tahun dengan jumlah 80 responden. Teknik pengumpulan datanya dengan menggunakan angket, dengan pengukurannya dengan skala likert. Kemudian angket yang telah dibuat dilakukan uji coba terlebih dahulu untuk menguji validitas dan reabilitasnya. Uji statistik yang digunakan adalah statsitik deskriptif dan statistik inferensial. Untuk uji hipotesisnya menggunakan uji koefisien kontigensi.

Pada uji statistik deskriptif untuk mencari skor tinggi, sedang, dan rendah maka perlu mencari nilai mean dan standart deviasi. Sedangkan uji statistic inferensialnya adalah dengan melakukan uji normalitas dan uji linearitas. Dalam uji normalitas

\footnotetext{
${ }^{4}$ Erni Agustina Setiowati, Gambaran Agresivitas Anak dan Remaja di Area Beresiko(Jurnal proseding temu ilmiah X ikatan psikologi perkembangan indonisia, (2007)online , 170.

${ }^{5}$ Menurut Kartono, "Perbandingan perilaku agresif antara remaja yang berasal dari keluarga bercerai dengan keluarga utuh,” Jurnal Psikologi Vol 3, no. 1 (2005): 1.
} 
menggunakan rumus kolmogorof smirnof dengan taraf signifikansi 1\%, dengan sebaran data dikatakan normal jika memiliki nilai signifikan lebih besar dari 0,05 dan uji linieritas lebih besar 0,05 maka terdapat hubungan yang linier. Dalam penelitian ini untuk menguji normalitas, linieritas dan kategori tinggi, sedang, dan rendah menggunakan IBS Statistic SPSS versi 21.

HASIL DAN PEMBAHASAN

Tabel 1

Tingkat pola asuh orang tua otoriter di Desa Plalangan

\begin{tabular}{|c|c|c|c|c|c|}
\hline & & Frequency & Percent & $\begin{array}{c}\text { Valid } \\
\text { Percent }\end{array}$ & $\begin{array}{c}\text { Cumulative } \\
\text { Percent }\end{array}$ \\
\hline \multirow{4}{*}{$\begin{array}{l}\text { Vali } \\
\mathrm{d}\end{array}$} & RENDAH & 10 & 12.5 & 12.5 & 12.5 \\
\hline & SEDANG & 52 & 65.0 & 65.0 & 77.5 \\
\hline & TINGGI & 18 & 22.5 & 22.5 & 100.0 \\
\hline & Total & 80 & 100.0 & 100.0 & \\
\hline
\end{tabular}

Dari data diatas dapat kita ketahui bahwa jumlah responden yang menerapkan pola asuh otoriter tingkat tinggi yaitu terdapat 18 orang, tingkat sedang 52 orang, tingkat rendah 10 orang tua. 
Tabel 2

Tingkat perilaku agresif remaja di Desa Plalangan

\begin{tabular}{|l|l|l|l|l|}
\hline & Frequency & Percent & $\begin{array}{l}\text { Valid } \\
\text { Percent }\end{array}$ & $\begin{array}{l}\text { Cumulative } \\
\text { Percent }\end{array}$ \\
\hline RENDAH & 15 & 18.8 & 18.8 & 18.8 \\
SEDANG & 49 & 61.3 & 61.3 & 80.0 \\
TINGGI & 16 & 20.0 & 20.0 & 100.0 \\
Total & 80 & 100.0 & 100.0 & \\
\hline
\end{tabular}

Dari data tersebut dapat kita ketahui bahwa jumlah responden yang berperilaku agresif ialah terdapat 16 remaja yang berperilaku agresif tinggi, yang berperilaku agresif sedang 49 remaja, sedangkan yang berperilaku agresif rendah ialah 15 remaja.

Tabel 3

One-Sample Kolmogorov-Smirnov Test

\begin{tabular}{|ll|l|}
\hline & & $\begin{array}{l}\text { Unstandardized } \\
\text { Residual }\end{array}$ \\
\hline $\mathrm{N}$ & Mean & 80 \\
Normal Parametersa, $\mathrm{b}$ & Std. Deviation & .0000000 \\
& Absolute & 3.03566791 \\
Most Extreme Differences & Positive & .103 \\
& Negative & .069 \\
Kolmogorov-Smirnov Z & & -.103 \\
Asymp. Sig. (2-tailed) & & .921 \\
\hline
\end{tabular}



a. Test distribution is Normal.
b. Calculated from data.

Berdasarkan hasil uji normalitas diketahui nilai signifikansi 0,365 lebih dari 0,05 maka dapat dikatakan bahwa nilai residual berdistribusi normal.

\section{Tabel 4}

\section{Uji linieritas}

\begin{tabular}{|c|c|c|c|c|c|c|c|}
\hline \multicolumn{8}{|c|}{ ANOVA Table } \\
\hline & & & $\begin{array}{l}\text { Sum of } \\
\text { Squares }\end{array}$ & Df & $\begin{array}{c}\text { Mean } \\
\text { Square }\end{array}$ & $\mathrm{F}$ & Sig. \\
\hline \multirow{6}{*}{$\begin{array}{l}\text { agresifitas } \\
\text { * pola asuh }\end{array}$} & & (Combined) & 1604.858 & 22 & 72.948 & 9.626 & .000 \\
\hline & Between & Linearity & 1308.793 & 1 & 1308.793 & 172.7 & .000 \\
\hline & Groups & Deviation from & 296065 & 21 & 14098 & & $0 ? 2$ \\
\hline & & Linearity & & & & & \\
\hline & Within Groups & & 431.942 & 57 & 7.578 & & \\
\hline & Total & & 2036.800 & 79 & & & \\
\hline
\end{tabular}

Berdasarkan tabel diatas dapat diketahui bahwa dilihat dari nilai sig. deviation from linierity yaitu 0,033. Karena nilai 0,033 > 0,05, maka terdapat hubungan yang linier antara variable pola asuh orang tua otoriter dengan perilaku agresif remaja. Kemudian dilihat dari nilai f hitung yaitu diketahui nilai df adalah 21; 57; 21 merupakan dk pembilang dan 57 merupakan dk penyebut. Karena F hitung $1.860<\mathrm{F}$ tabel 2.12. maka disimpulkan bahwa ada hubungan yang linier dari pola asuh orang tua otoriter dengan perilaku agresif remaja. 
Tabel 5

\title{
Nilai korelasi pola asuh otoriter dengan perilaku agresif remaja
}

\author{
Correlations
}

\begin{tabular}{|ll|l|l|}
\hline & & Otoriter & Agresif \\
\hline $\begin{array}{l}\text { Otorit } \\
\text { er }\end{array}$ & $\begin{array}{l}\text { Pearson } \\
\text { Correlation }\end{array}$ & 1 & $.802^{* *}$ \\
& Sig. (2-tailed) & & .000 \\
& $\mathrm{~N}$ & 80 & 80 \\
& Pearson \\
Agresi & Correlation & $.802^{* *}$ & 1 \\
$\mathrm{f}$ & Sig. (2-tailed) & .000 & \\
& $\mathrm{~N}$ & 80 & 80 \\
\hline
\end{tabular}

Berdasarkan nilai signifikansi sig.(2-tailed): dari table output di atas diketahui nilai sig. (2-tailed) antara pola asuh otoriter $(\mathrm{X})$ dengan perilaku agresif remaja (y) adalah sebesar $0,000<0,05$, yang berarti terdapat korelasi yang signifikan antara variable pola asuh orang tua dengan prilaku agresif remaja atau ada hubungan. Di dalam pedoman derajat hubungan 0,802 termasuk dalam korelasi sempurna dan bentuk hubungannya adalah positif.

Nilai $\mathrm{r}$ hitung (person correlations) diketahui nilai $\mathrm{r}$ hitung untuk hubungan pola asuh orang tua yang otoriter(X) dengan prilaku agresif remaja (Y) adalah sebesar 0,802> r tabel 0,2199, maka dapat disimpulkan bahwa ada hubungan antara variable pola asuh orang tua otiriter dengan prilaku agresif remaja.

Berdasarkan tanda bintang (*) spss dari output diatas diketahui bahwa pearson correlation antara masing-masing variable yang dihubungkan mempunyai dua tanda bintang $(* *)$, ini berarti terdapat korelasi antara variable yang dihubungkan dengan taraf 
signifikansi $1 \%$. Pada taraf signifikan $1 \% \mathrm{r}$ hitung $=0,802>\mathrm{r}$ tabel 0,219 maka Ha diterima dan Ho ditolak.

\section{PENUTUP}

Berdasarkan hasil penelitian dan pembahasan, dapat ditarik beberapa kesimpulan. Pertama, tingkat pola asuh orang tua otoriter di Desa Plalangan yaitu masuk dalam tingkat sedang. Hal ini dapat diketahui dan dibuktikan lewat analisis data yang telah dilakukan yaitu sebanyak 18 (22,5\%) orang, tingkat sedang sebanyak 52 (65\%) orang, tingkat rendah sebanyak 10 (12,5\%) orang. Kedua, tingkat perilaku agresif remaja di Desa Plalangan yaitu masuk dalam tingkatsedang. Hal ini dapat diketahui dan buktikan lewat analisis data yang telah dialakukan yaitu $16(20 \%)$ remaja, tingkat sedang sebanyak 49 (61,3\%) remaja, tingkat rendah sebanyak 15 (18,8\%) remaja. Ketiga, ada hubungan yang signifikan antara pola asuh otoriter dengan perilaku agresif remaja di Desa Plalangan. Hal ini sesuai dengan perhitungan hipotesis yaitu pada taraf signifikan $1 \% \mathrm{r}$ hitung $>\mathrm{r}$ table yaitu $=0,802$ dan $\mathrm{r}$ table $=0,2199$ oleh karena nilai $\mathrm{r}$ hitung lebih besar dari r table maka dinyatakan bahwa Ha diterima.

\section{DAFTAR RUJUKAN}

Erni Agustina Setiowati. "Gambaran Agresifitas Anak Dan Remaja di Area Beresiko. Jurnal Proseding Temu Ilmiah X Ikatan Psikologi Perkembangan Indonisia, 2007.

Kartono. Perbandingan perilaku agresif antara remaja yang berasal dari Keluarga bercerai dengan keluarga utuh.Jurnal Psikologi Vol 3, no. 12005.

Tim Penyusun Kamus Pusat Bahasa. Kamus bahasa indonisia. Jakarta: Balai Pustaka, 2002.

Nurhalimah, siti, media sosial masyarakat pesisir: refleksi mahasiswa bidikmisi, deepublish:2019.

Walgito Bimo, bimbingan penyuluhan di sekolah. Yokyakarta: Fakultas Psikologi UGM, 1989. 